\title{
Las virtudes cívicas y su uso en el IUS contemporáneo*
}

\section{Civic virtues and their use in contemporary IUS}

\author{
Carlos Augusto Martínez Orozco ${ }^{* *}$
}

\begin{abstract}
* El artículo hace parte del proyecto académico que viene en proceso de construcción y que consiste en la socialización para América Latina de los textos de Quentin Skinner, historiador de las ideas de la Universidad de Cambridge. La socialización del presente artículo fue realizada en el I Encuentro Internacional de los Derechos Sociales en las Constituciones Latinoamericanas con la ponencia titulada El aporte de las virtudes cívicas a la dignidad humana.

** Doctor en Pensamiento Político y DEA. Profesor Universidad La Gran Colombia Sede Armenia. Correo electrónico: publicsolver@ gmail.com Dirección de correspondencia institucional: Carrera 14 No 7-46 Armenia, Quindío, Colombia.
\end{abstract}

Cómo citar: Martínez, C.A. (2018) Las virtudes cívicas y su uso en el ius contemporáneo. Inciso, 20(2); 37-55.

Recibido: 05/09/2018 Revisado: 17/11/2018Ａceptado: 10/12/2018

DOI: http://dx.doi.org/ 10.18634/incj.20v.2i.894

\section{Resumen}

El principal propósito del presente trabajo es comprender la importancia del republicanismo y la fuerte influencia que tiene para su construcción el pensamiento clásico, especialmente lo concerniente a las fuentes jurídicas. Para ello se ha dividido en dos grandes apartados. De una parte, se dan a conocer algunas generalidades de la Escuela de Cambridge y de Quentin Skinner. Por otra parte, se utiliza su reciente publicación Forensic Shakespeare para explicar el origen del lenguaje jurídico, su conformación y el uso que de él se hace en diferentes escenarios de actuación como por ejemplo, algunas de las obras de Shakespeare. Esta comprensión de algunos elementos del escenario renacentista permite desde el abordaje de la historia conceptual y de las ideas entender la necesidad de retornar a las fuentes clásicas para una mejor construcción de los procesos de pensamiento y narrativa del lenguaje jurídico contemporáneo y así mismo, explicar la consolidación del republicanismo.

Palabras clave: Historia constitucional, Humanidades, Pensamiento, ética, ciudadanía.
The main purpose of this paper is to understand the importance of republicanism and the strong influence that classical thought has had on its construction, especially regarding legal sources. For this, it has been divided into two large sections. On the one hand, there are mentioned some generalities of Cambridge School and Quentin Skinner. On the other hand, it is used a recent publication, Forensic Shakespeare, in order to explain the origin of legal language, its conformation and its use in different performance scenarios, such as, for example, some of Shakespeare's plays. This understanding of some elements of the Renaissance scenario allows to understand, from the approach of conceptual history and ideas, the need to return to classical sources for a better construction of thought and narrative processes of contemporary legal language; and likewise, to explain the consolidation of republicanism.

Keywords: Constitutional history, Humanities, Thought, ethics, citizenship. 


\section{Introducción}

En 1985, en la segunda mitad de siglo y a pocos años de darle fin al controvertido siglo XX, apareció publicado por parte de la editorial Cambridge University Press, la obra The Return of Grand Theory in the Human Sciences. Su portada, quizá como un signo premonitorio para la sociedad de fin de milenio, refresca una escena construida desde la imaginación del pintor renacentista Rafael Sanzio. En ella se ve a un grupo de hombres de largas túnicas, unos hablando, otros escribiendo, algunos ensimismados y perdidos en la abstracción de sus propias ideas.

En este recuadro extraído del fresco original que supera los treinta metros de área llamado $L a$ Escuela de Atenas, que se encuentra ubicado en el Musei Vaticani en la Viale Vaticano en Roma, aparecen personajes de un mundo clásico que empezaba a redescubrirse en el Renacimiento: Averroes, Pitágoras, Alcibíades, Antístenes, Hipatia, Parménides, Sócrates, Heráclito, Platón y Aristóteles. Ejemplos de quienes, aún muchas veces en contra de la corriente, se dedicaron, entre otras cosas, al humano ejercicio de pensar.

Se rememora la portada de este vigente texto por dos razones. La primera, se ha podido permear a través de los escritos de los teóricos actuales de diferentes escuelas y líneas académicas, una creciente tendencia a fortalecer parte de sus argumentos narrativos con los autores y los denominados, textos clásicos.

La segunda, las imágenes que aparecen en esta portada y su sugestivo título invitan a reflexionar en la importancia, vigencia $\mathrm{y}$ necesidad de retornar a las obras clásicas para generar procesos de pensamiento que aborden lo que la moderna sociedad de consumo con sus avasalladoras tendencias tecnológicas ha dejado de lado: los seres humanos y su desenvolvimiento social, político y económico. Ya lo mencionó
Franc Ponti, profesor de innovación, cuando habla de construir "menos tecnología y más humanidades".

En este sentido, volver la mirada al pasado y revisar de nuevo sus desaciertos y logros será una de las estrategias fundamentales en la edificación del tejido social del siglo XXI. La democracia moderna debe ingresar a un proceso de incubación para que pueda resurgir como el ave fénix y organizar de una forma más adecuada el mundo contemporáneo, tal y como se observó en octubre de 2008, cuando The Financial Times publicó el titular "Capitalismo en convulsión" (Martínez, 2013, 247-274), hay que fortalecer la sociedad con una nueva promesa de valor y ante todo, la democracia como la vía más equitativa para ejercer la gobernanza.

Como se ha denotado en el anterior ejemplo, hay que retornar a los autores clásicos y especialmente recuperar de ellos, entre otras cosas, la idea de las virtudes cívicas (Skinner, 2002, 264-285; Bocardo, 2007, 183). Es decir, aunque de espacios de tiempo y contexto diferente, a través de sus escritos se puede permear para los lectores contemporáneos, variables conceptuales de una vigencia absoluta en el presente. Hay que retornar a la teoría clásica y engrandecer, de nuevo, a las ciencias humanas. Por ejemplo, al revisar de nuevo las ideas del Buen Governo que ya desde el siglo XIV se vienen aplicando en las sociedades republicanas, se empieza a gestar una sociedad concertada, incluyente y no corrupta.

Es precisamente desde esta orientación académica que se proyecta el presente trabajo. La idea de escribir el presente artículo surgió desde la recepción de la obra Forensic Shakespeare en el año 2015. Seis meses fueron empleados en la comprensión y análisis del texto. Los meses restantes al verano de 2016 que inicia para algunas zonas de Sudamérica en el mes de noviembre, se utilizaron para la adaptación de los párrafos seleccionados y los complementos necesarios provenientes de otras lecturas. 
De allí se desprende el sencillo pero principal propósito de este escrito que consiste en ofrecer un artículo general que permita comprender la fuerte influencia que tuvo el Renacimiento y su construcción humanista y jurídica del pensamiento clásico expresado a través de los autores y sus obras. El trabajo se ha dividido en dos apartados generales. De un lado, se darán a conocer unos datos biográficos de Quentin Skinner y la Escuela de Cambridge, como manera de contextualizar a uno de los más importantes historiadores de las ideas del mundo contemporáneo. Se utilizarán apartados de su reciente publicación, Forensic Shakespeare, para explicar el retorno a los orígenes del lenguaje jurídico a través de la mirada de la historia y así percibir los elementos útiles al Ius contemporáneo. Este escenario de pensamiento permitirá especialmente la comprensión del Ars humanitatis, entre otros, a partir de la periodización que utiliza el mismo Skinner sobre Shakespeare y la escritura de sus obras: la primera entre 1594 y 1600 . La segunda, entre 1603 y 1605. La utilización de un lenguaje jurídico heredado del pensamiento clásico se expresa a través de las obras Romeo and Julieth, The Merchant of Venice, Julius Caesar, Hamlet, Othello, Measure for Measure y All's Well that Ends Well.

La novedad y trascendencia de esta segunda parte se centra en permitir conocer un lenguaje jurídico que se utilizó no solo en la narrativa shakespeariana sino también en la construcción del entramado jurídico que aun hoy se aplica. Es necesario volver a creer en las actividades provenientes del ejercicio jurídico como mecanismo de estabilidad democrática. Una sociedad que juzga en derecho y equidad está proclive, al menos, a la obediencia de sus ciudadanos. Por el contrario, una sociedad que percibe las malas actuaciones en derecho, de seguro perderá credibilidad en el sistema y generará un desequilibrio abrumador. Es precisamente en este último apartado en el que tiene mayor relevancia el estudio del pensamiento clásico y los aportes jurídicos que llegaron al Renacimiento y se irrigaron por muchas partes del mundo. Es tiempo de empezar a construir la idea del buen gobierno que ya se profesaba desde el siglo XIII. Recuperar el interés por los ejercicios académicos de los buenos juristas que desde su saber ayuden a construir como en los tiempos clásicos de la sociedad, un futuro humano más esperanzador.

De hecho, no hay que perder de vista que el estudio del republicanismo es fundamental en estos momentos de la historia. Especialmente ahora que hay un fuerte retorno a los gobiernos de derecha, al nacionalismo moderado que puede convertirse en xenófobo y a la exclusión de no nacionales en el eje global. Precisamente la fuerza que ha tomado el estudio del republicanismo y las virtudes cívicas se ve reflejado y coincide con un hecho trascendental: la relevante inauguración del Centre Européen des Études Républicaines el 24 de noviembre de 2016 en París, que centra su mayor interés en el estudio y consolidación de estos temas.

\section{El historiador de las ideas: Quentin Skinner}

El inglés Quentin Robert Duthie Skinner, mejor conocido como Quentin Skinner, nació el 26 de noviembre en el umbral de la Segunda Guerra Mundial en 1940, en una pequeña localidad que durante el siglo XIX se convirtió en el centro internacional de la manufactura textil: Oldham en Lancashire, Inglaterra (Martínez, 2014, 9-20; Martínez, 2013; Martínez, 2012, 78-85; Martínez, 2006, 33-62).

Skinner inició sus estudios primarios en Bedford School, una escuela pública para jóvenes, ubicada en la localidad de Bedfordshire, a no muy lejana distancia de Cambridge. Esta escuela fue fundada por el rey Eduardo VI, iniciando la segunda mitad del siglo XVI, en el año de 
1552. Además, recibió aportes del mercante, sir William Harpur, quien llegó a convertirse en lord mayor de Londres. Cabe señalar que fue en este periodo, comenta Skinner, cuando "a los once años de edad estuve muy enfermo, con tuberculosis, y tuve que estar un año apartado de la escuela...".

Posteriormente y tras haber realizado una destacada labor en sus estudios, Skinner, continua con su formación básica en Gonville and Caius College, uno de los muchos centros educativos que forman parte de la Universidad de Cambridge. Este centro de estudios fue inicialmente fundado como Gonville Hall por parte de Edmund Gonville en el año de 1348. Tras superar los problemas medievales, es refundado en 1557 con el nombre de Gonville and Caius College, por parte del físico Jhon Caius, convirtiéndose de esta manera en uno de los más tradicionales y reconocidos colegios de Cambridge.

En esta institución, Skinner no solo logró ser egresado sino que es elegido desde 1962, con apenas veintidós años, honorary fellow, gracias a los excelentes resultados académicos obtenidos, especialmente en el área de la Historia. Ese mismo año, Skinner, obtiene el título de bachelor of Arts en la Universidad de Cambridge. Tres años más tarde y en la misma universidad obtiene el grado de master of Arts. La continuidad de sus estudios le permite desde entonces convertirse en docente de la institución fundada por primera vez hacia 1437 por William Bynham y posteriormente por Lady Margaret Beaufort en 1505, el Christ's College, filial de la Universidad de Cambridge.

La década de los setenta traería para él nuevas expectativas académicas que le permitieron canalizar su vinculación con The Institute for Advanced Study ubicado en Nueva Jersey, Estados Unidos. Este importante centro de investigación es considerada la casa de Albert Einstein, Oppenheimer y Michael Walzer, entre otros destacados teóricos. Además, allí Skinner tuvo la oportunidad de conocer y compartir el diálogo académico con Thomas Samuel Kûhn, el recordado autor de la obra La estructura de las revoluciones cientificas, y con Clifford Geertz, uno de los grandes teóricos en la construcción del concepto de cultura. Además, como señala el mismo Tony Judt, “en la década de 1960, Quentin Skinner escribió una serie de brillantes artículos reformulando la metodología de la historia de las ideas y demostró lo incoherente que era escribir historia intelectual sin poner las ideas en su contexto..." (Judt y Snyder, 2012, 253).

Una de las más importantes distinciones académicas fue convertirse a partir de 1996, en regius professor de Historia Moderna de la Universidad de Cambridge. El regius es una categoría docente fundada en 1724 por Jorge I de Inglaterra. Ha sido catedrático de humanidades en la Universidad de Londres. La grandeza de sus postulados académicos lo ha llevado a ser visiting fellow en las Universidades de Australia, Oxford, Washington, París, Berlín e Italia. En España fue el conferencista principal de las Jornadas sobre Republicanismo que organizó la Universidad de Sevilla bajo la dirección de Enrique Bocardo Crespo, hacia comienzos de la primavera del año 2007.

Desde 1979 ha recibido importantes distinciones académicas y reconocimientos honoríficos como por ejemplo, la Medalla del College de France, el Premio sir Isaiah Berlin de la British Political Studies Association y el Balzan Price. Es miembro académico honorario de importantes universidades del mundo, entre ellas, la Universidad Adolfo Ibáñez de Santiago de Chile, donde fue condecorado en octubre del año 2009.

Eloy García, en la nota introductoria que realiza a propósito de la reciente publicación en castellano de la obra de Quentin Skinner, El artista y la filosofía politica: el buen gobierno de 
Ambrogio Lorenzetti, afirma:

No resulta ocioso recordar que Quentin Skinner encarna el prototipo del mejor escolar británico. Regius Professor de Historia del Christ's College de la Universidad de Cambridge; Doctor Honoris Causa por once prestigiosas Universidades, entre ellas Harvard, donde -y en atención al dato- lo es por derecho; Profesor en el Colegio de Francia, investigador en el Centro de Estudios Avanzados de Princeton, y en el Wissenschaftskolleg de Berlín. Autor de una docena de libros, y editor de otros tantos. Responsable de numerosos artículos y de notables trabajos colectivos...".

Para la fecha de la culminación de este artículo, a finales de noviembre de 2016, Quentin Skinner se encuentra radicado en Londres y trabaja para Queen Mary University, dedicado a la reconstrucción de las estructuras de las teorías republicanas, es decir, como comenta en la publicación de su obra Una genealogía del estado moderno, realizada por la Universidad Adolfo Ibáñez de Chile en el año 2009:

Me dedico trazar la genealogía del estado moderno para descubrir que nunca ha existido un concepto único al que el término estado se refiera. Si bien entre los pensadores políticos contemporáneos predomina la perspectiva que considera al estado como el nombre de un aparato de gobierno establecido, planteo la conveniencia de comprender el estado como el nombre de una persona definida de quien se dice que tiene voluntad en virtud de que la voluntad de algún poder público autorizado le ha sido atribuida.

Una de sus más recientes presentaciones académicas fue realizada el 25 de noviembre de $2016^{1}$ junto a Philip Pettit, Celine Spector, Vincent Peillon y Pierre Rosanvallon en el Colloque international: Modernités Republicaines en la École Normale Supérieur con la ponencia Situtating Republican Liberty ${ }^{2}$.

1 En un correo electrónico fechado el 25 de noviembre de 2016, Quentin Skinner comenta que "I am writing this note sitting in a hotel in Paris, where I have been lecturing at the inaugural conference of a new French Center for the study of Republicanism".

2. Stephan Soulié, organizadora del Coloquio Modernités Républicaines, a través de
Forensic Shakespeare y el retorno a los orígenes del lenguaje jurídico a través de la mirada de la historia

La obra Forensic Shakespeare tuvo en su consolidación y finalización varias etapas. A finales del 2011 se presentaron los argumentos para la realización del libro en Clarendon Lectures de la Universidad de Oxford. El seminario fue organizado por David Norbrook con apoyo de Richard McCabe, Seamus Perry y Katy Routh. A finales de 2012, un año después, fue presentada una versión revisada de los argumentos expuestos en Clarendon Lectures. En esta oportunidad el trabajo fue expuesto al Trinity College de Cambridge, allí colaboraron Boyd Hilton, Richard Serjeantson, Caroline Humphrey, Martin Rees y Adrian Poole, entre otros.

Sin embargo, el punto de partida para la escritura final de la obra se originó después de haber tomado parte en dos conferencias en el año 2006. La primera fue organizada en Cambridge por Sylvia Adamson, Gavin Alexander y Katrin Ettenhuber denominada Renaissance Figures of Sppech. La segunda fue organizada por David Armitage, Conal Condred y Andrew Fitzmaurice en el Humanities Research Centre of the Australian National University, sobre Shakespeare y el pensamiento político.

El proceso de escritura final del texto se inició después de que Skinner se trasladara de Cambridge University a Queen Mary University en el año 2008. Allí se concluye el primer borrador del trabajo que circuló entre académicos para consolidar su finalización en el año 2014.

El libro, como dice Skinner, es un continuo esfuerzo para comprender el lugar del ars rhetorica en la historia de la cultura del

correo electrónico de fecha 1 de diciembre de 2016 envía el resumen de la ponencia de Skinner: "Within modern political theory, liberty has generally been defined as absence of interference or constrain (tradition A), but some theorist have doubted whether the presence of liberty is best understood as an absence, and have instead attempted to connect the idea with specific patterns of moral behaviour (tradition B). I argue that, to connect the idea with specific patterns of moral behaviour (tradition B). I argue that, to
understand the distincly 'republican' view of liberty, it needs to be seen in part as a protest against both these lines of argument. Against tradition (B) republicans argue that the presence of liberty is always marked by absence not of constrain but of dependence". 
Renacimiento y ante todo de observar cómo en muchos casos la dramática obra de Shakespeare está delineada con la retórica jurídica de los tratados clásicos retomados en este mismo periodo histórico.

\section{Orígenes de la consolidación del ars rhetorica y el studia humanitatis}

Sin lugar a equívocos el ars rhetorica ${ }^{3}$ ocupa un lugar privilegiado en la historia de la cultura del Renacimiento. Desde esta premisa, acorde con la marcada influencia que ha tenido esta cultura a lo largo y ancho del mundo, especialmente en lo que respecta al resurgimiento de las ideas retóricas romanas que competen a la orientación para la construcción teórica necesaria para conducir la vida pública, es posible afirmar que el andamiaje jurídico que hoy nos soluciona o afecta tiene en su haber grandes fragmentos de lo propuesto desde el ars rethorica.

Por otra parte, es claro y demostrado que existen varios principios que vinculan el discurso jurídico contemporáneo utilizado de forma oral o escrita en las diferentes escuelas de Derecho del mundo con los aportes conceptuales que han emergido de este contexto. Si se analiza entre líneas el discurso narrativo construido y utilizado en The Rules of Equity, The Common Law, el Derecho anglosajón o americano, oral o escrito, cuenta con la más extensa fundamentación proveniente del periodo renacentista, especialmente el que fue irrigado después que los nativos americanos descubrieron que existían los europeos a partir de 1492.

Uno de los puntos de partida con fines prácticos se puede referenciar a partir del studia humanitatis. Este concepto ciceroniano que ha sido traducido por algunos estudiosos modernos como "las humanidades" y sus derivados, tales como "humanismo", "humanistas" y otros más,

3 A partir de este apartado, se ha utilizado el contenido de la obra Forensic Shakespeare, con fines académicos para el presente artículo. En algunos casos muy puntuales se hizo adaptación expresa al idioma español. En otros apartados se ha dejado en inglés para dar preponderancia a la intención narrativa de Quentin Skinner en su lengua materna. ha sido vital en el proceso de construcción de muchas variables de lo que hoy forman esos corpus jurídicos. Sin embargo, y a pesar de la dualidad que se ha presentado entre quienes han usado el concepto con vaguedad y quienes desean expulsarlo de todos los relatos futuros del pensamiento de principios de la época moderna, se podría afirmar acorde con los planteamientos de Skinner que

La solución está en limitar su empleo a su original sentido renacentista, utilizándolo simplemente para referirse a los estudiosos y protagonistas de un grupo particular de disciplinas centradas en torno al estudio de la gramática, la retórica, la historia y la filosofía moral (Skinner, 1985) ${ }^{4}$.

Para el presente estudio se utilizarán los aportes que se generaron en el pre y posrenacimiento por parte de los autores clásicos. La clave textual se centra en obras como por ejemplo, Rethorica and Herennium de autor anónimo que fue finalizada hacia el año 80 a.C., algunos tratados neociceronianos como Art of Rhetorique de Thomas Wilson y especialmente, De Inventione de Cicerón, escrita hacia el año 90 a.C.

No obstante, como se ha señalado de manera reiterativa, se hará énfasis en la reciente publicación de Quentin Skinner, Forensic Shakespeare, en la que se esboza de manera muy específica, cómo a través de los elementos narrativos de Shakespeare se usa como fuente predilecta, -entre muchas otras-, la obra de Cicerón que refleja cinco elementos fundamentales para la construcción del derecho oral desde la lógica jurídica: Inventio, Dispositio, Elocutio, Pronuntiatio y Memoria (Skinner, 2014)

4 Jhon Burrow comenta que el término humanista procedía de las humanidades, uno de los componentes del currículo de estudios, en lo fundamental consistía en la formación en materia de retórica latina basada en una estrecha proximidad con los modelos antiguos mejor considerados, en especial, Cicerón y Séneca, aunque incluía también a Salustio, Tito Livio y Virgilio (Burrow, 2009, 339).

5 Desde la perspectiva jurídica, llama la atención el capítulo tercero, The Open Beginning y el sexto, The Judicial Narrative. 


\section{Cicerón de Roma}

Uno de los aportes de mayor relevancia para el debate jurídico que en sus inicios fue mores y luego se convirtió en ius, bien oral o escrita tras la fusión de ideas de Grecia y Roma, se encuentra en la forma cómo ellos lograron hacer que el derecho fuera la expresión de las leyes de la naturaleza humana. No en vano se hace referencia en que "Sócrates puede haber tenido razón al ser el primero, según dice Cicerón, en bajar la filosofía del cielo asentándola en las ciudades e introduciéndola en las casas, obligándola a investigar las formas y normas de comportamiento de los hombres" (Blumenberg, 2008, 239; Blumenberg, 2009, 35) ${ }^{6}$.

Es precisamente desde esta mirada que Marco Tulio Cicerón construye sus postulados. Nacido en Roma el 3 de enero de 106 a.C., su gran visión la enmarcó en permitir a la sociedad romana el conocimiento de la escuela filosófica helénica, la creación de un extenso vocabulario en latín, el desarrollo de sus ideas políticas aproximadas a lo que posteriormente sería el buen gobierno, entre muchas otras.

$\mathrm{Su}$ formación en derecho se dio en Roma y compartieron academia junto a él, Escévola, Mario "el joven", Sulpicio y su gran amigo, Ático, con quien sostuvo una abundante correspondencia:

El toque de genio en el pensamiento de Cicerón se encuentra en el hecho de que emprendió la sistematización de los puntos de vista encajados en la jurisprudencia romana, y en que los situó dentro del marco de las ideas filosóficas platónicas, aristotélicas y estoicas... en su obra encontramos hábil uso de la retórica, como arte de persuasión

\footnotetext{
6La importancia de Cicerón no solo se centra en los aspectos jurídicos. Sus aportes en la poesía fueron fundamentales: "Cicero's speech in Defence of Archias, delivered in 62, contains the fullest extent statement of the value of such civically oriented poetry. Cicero 's arguments are shaped by the circumstances of the case he is pleading; specifically, his aim is to counteract xenophobic feelings toward a Greek client-poet by playing up the value for Rome and Romans of poetry Archias had written to honor his patron Luculli. But for that very reason it is likely that he stresses the considerations that would have been most effective in influencing a Roman jury`s opinion" (Tarrant, 1997, 170).
}

tal como había sido sistematizado por Aristóteles. La doctrina ciceroniana de la interpretación constituye un enorme logro jurídico en su claridad sistemática y en sus detalles (Friedrich, 1997, 54).

Parte de los argumentos que llevaron a su muerte se centran en el hecho de su constante defensa del republicanismo frente a otros sistemas de gobierno. De hecho, Cicerón es constantemente atacado por igualar monarquía con tiranía. No en vano en sus escritos se hace referencia de manera constante al Bonus o el Optimus Status Reipublicae, que a finales del siglo XIV ya se refería al Estado o la condición real de Commonwealth. Al igual que su insistencia permanente en argumentar que se debía legislar para un estado libre ${ }^{7}$ en el que la ley tuviese preponderancia frente a lo demás: Salus populi suprema lex, es decir, la seguridad del pueblo debería ser tratada por la suprema ley. En este sentido, Cicerón advierte:

Uno de los rasgos característicos de la vida en Roma eran los Censores, cargos públicos establecidos desde antiguo que se encargaban de velar por que las maneras y la moralidad romana se mantuviera dentro de un orden. La valoración del carácter también dio un nuevo enfoque a la oratoria del Senado, de los tribunales y a la forma de señalar las ocasiones públicas: el elogio (Laudatio), vinculado a menudo a los funerales, $y$, en la

7 En una serie de textos de derecho consuetudinario medieval aparecen reflejados muchos de los postulados propuestos por Cicerón, sobre todo, aquellos de Bracton y Littleton. Estas fueron las autoridades a las que sir Edward Coke y sus seguidores les gustaba invocar en los tiempos iniciales del parlamento estuardo. Henry de Bracton en su obra, De Legibus et Consuetunibus Angliae de 1260, hizo una distinción en su capítulo de apertura entre "personas libres" y "esclavos". Definió como esclavo a cualquiera que "vive sometido bajo el dominio de alguien más". En el siglo XV sir Thomas Littleton en el tratado Un Lyver de Exposicion de Parcell de les Ternures trazó un sistema similar de distinciones entre hombres libres, villanos y esclavos, afirmando que un esclavo es alguien cuya falta de libertad es tal que su personalidad -y no solo como con un villano- es sub potestate, bajo el poder o la compasión de alguien más. La característica más llamativa de estas definiciones (aunque más tarde los abogados del Common Law, hicieron todo lo posible para ignorar el hecho) es que deben totalmente su fraseología, a los análisis de libertad y esclavitud al inicio del Digesto de la Ley Romana. Allí por primera vez se informó que "la división fundamental dentro del derecho de la persona es que todos los hombres y las mujeres son, libres o esclavos". Entonces se nos da una definición formal de esclavitud: "Esclavitud es una institución del ius gentium por el cual alguien es, contario a la naturaleza, atado al dominio de alguien más". Este concepto a su vez, sirve para dar una definición de libertad individual. Si alguien, en una asociación civil, es esclavo o libre, entonces un civis o un súbdito libre debe ser alguien que no está bajo el dominio de alguien más, sino que es sui iuris, capaz de actuar en derecho propio. Igualmente continúa, diciendo que, lo que esto significa para alguien con falta de condición de un súbdito libre debe ser para esa persona no ser sui iuris sino que, en lugar de eso, ser sub potestate, bajo el poder o sometido a la voluntad de alguien más (Martínez, 2014, 7-30). 
acusación, la invectiva, formidable ejercicio de difamación que tuvo a Cicerón entre sus mayores virtuosos (Burrow, 2009, 135-136).

La muerte de Marco Tulio Cicerón de Roma acaeció el 7 de diciembre del 43 a.C. El cónsul ordenó su asesinato, así como que su cabeza y sus manos se expusieran al público. Como lo ha señalado Carl Joachim Friedrich, "Cicerón fue hostil a la solución dictatorial y monárquica del problema del imperio y, finalmente pagó con su vida esta convicción, mártir de la vieja civitas romana como antes lo había sido Sócrates de la Polis griega" (Friedrich, 1997, 53).

Cicerón incluye expresamente la astronomía, la geometría, la dialéctica y el derecho civil entre las actividades en las que se reconoce su pertenencia a tareas de conocimiento morales y dignas y a las que con razón se dedica esfuerzo y esmero:

La restricción que él añade a continuación no tiene que ver con una exclusión a causa del objeto, sino con la economía del propio sujeto actuante. Todo eso serían habilidades de la investigación de la verdad y el ocuparse de ellas no debería ser un impedimento para el desempeño de las obligaciones cotidianas, ya que solamente a las acciones se les puede reconocer una cualidad moral (Blumenberg, $2008,279)^{8}$

Cicerón legó a los "medievales varios escritos retóricos importantes: De Oratore, De Inventione (del que el Ad Herennium se considera la segunda parte) y las Disputas Tusculanas (Tusculanae Disputationes) que habían ejercido una influencia decisiva en la conversión de Agustín. Es el primer latino en haber hecho de la memoria, hacia el final del De Inventione, una parte de la virtud de Prudentia, al lado de la Intelligentia y de la Providentia" (Ricoeur, 2008, 89)

8 De hecho, no hay que olvidar, comenta Blumenberg, que Agustín señala que fue Cicerón quien despertó, cuando estaba inmerso en su carrera de retórico, a más altas actividades intelectuales. Además, recurriendo a Cicerón, Agustín ve resaltado precisamente en el escepticismo, una reivindicación esencial del hombre, la absoluta primacía -sin la mediación ya de la teoría- de la realización de su felicidad.

9 Es de notar que no solo Cicerón contribuyó en la recepción de los supuestos cívicos
Sin embargo, como se ha señalado anteriormente, una de las líneas de trazabilidad desde las que se puede valorar la obra de Cicerón, es la relacionada con sus aportes a la construcción de elementos que hoy se usan en el debate jurídico, tales como Inventio, Dispositio, Elocutio, Pronuntiatio y Memoria.

No en vano se ha establecido que los conceptos básicos de Cicerón han dominado el pensamiento jurídico durante mil años:

La Constitución o Politeia recibe, decididamente, una posición preeminente. Los otros tipos de derecho deberán tener como base la Constitución, distinción esta que más tarde, tomó por su cuenta y desarrollo Cicerón. Esta idea pasó a ser propiedad común del pensamiento jurídico occidental (Friedrich, 1997, 54) ${ }^{10}$.

Cicerón afirma expresamente que el conocimiento del derecho (Juris Disiplina) "no puede derivarse de las decisiones de los Pretores ni de las Tablas de la Ley, sino únicamente de la Filosofía... hemos nacido para la justicia, y la ley no se funda en la opinión, sino en la naturaleza misma del hombre" (Friedrich, 1997, 52).

Marco Tulio Cicerón de Roma marcó un lugar decisivo en la consolidación de la narrativa jurídica necesaria para estructura los elementos del derecho que posteriormente servirán de enlace para la consolidación del Ius como la piedra angular de las sociedades modernas. Se concluye que otro de los grandes aportes de al pensamiento prehumanista del Trecento, también aportaron Séneca, Salustio y otros tratadistas de la república romana.

10 De otra parte, se menciona que "en una carta escrita por Pier Paolo Vergerio en 1394, él mismo se imagina ser Cicerón, respondiendo a las expresiones de disgusto de Petrarca en su obra Vita Solitaria, donde argumenta que Cicerón es muy devoto a los asuntos públicos", sin embargo, responde que "That the man who surpasses all others in his nature and way of life is the one who bestows his talents on the government of the respublica and in working for the benefit of everyone" (Skinner, 2007, vol. II, 6-7). Similar comentario había realizado años antes Skinner: "En una carta escrita por Vergerio en 1394, se imagina ser Cicerón, replicando a las expresiones de disgusto de Petrarca por su deseo de mantenerse dedicado a los asuntos políticos. Hace insistir a Cicerón en que, "siendo siempre deber de un hombre esforzarse por ser querido primero por su propia patria y después por toda la humanidad", esto hace enteramente justificable el haber deseado "permanecer en todo momento dedicado al negotium"'" (Skinner, 1993, 132). Años más tarde, John Milton en su Defensio, evoca las palabras de Cicerón en su cuarta Filípica cuando menciona: "¿qué causa de guerra puede ser más justa que aquella que repudia la esclavitud?". Esto enlaza con la permanente asociación que tenía Cicerón con la filosofía platónica, especialmente aquella que busca la felicidad para estar en paz: Vivere ut Velis. 
Cicerón a partir de su obra De Inventione fue la construcción de dos cualidades cardinales para hablar de manera persuasiva y convencer: la ratio o razón en combinación con oratio o el poder del habla o la oratoria.

\section{La influencia de Cicerón en el Renacimiento}

Hans Barón ha difundido la creencia de que antes de comienzos del quattrocento no hubo ninguna expresión de preferencia teórica por el republicanismo en el pensamiento político italiano, y por tanto, ninguna apreciación de la "doctrina cívica" de Cicerón o su lealtad a los valores políticos republicanos. Puede argüirse, sin embargo, que los elementos principales de esta conciencia histórica humanística se formaron en realidad con la llegada de la teoría política escolástica a Italia, casi un siglo antes. Ya Marsilio piensa en Cicerón no solo como sabio estoico, sino antes bien como prudente funcionario público... (Skinner, 1993, 76).

Sin embargo, y en un análisis más detallado de los documentos utilizados y el contexto del cual emergieron,

Skinner sostiene $-\mathrm{y}$ lo ilustra de manera magistral- que el pensamiento republicano cívico nace ciento cincuenta años atrás, en las Ciudades-Estado italianas del Duecento (en los Ars Dictaminis compuestos para dictadores, y en tratados de gobierno como Oculus Pastoralis o Li libres dou Trésor) y toma el acervo argumental con el que construye su racionamiento -que es el de Lorenzetti- de un conjunto de obras que beben en fuentes romanas y no en una política de Aristóteles, por entonces todavía no recuperada. Es en los De Oficiis y De Inventione de Cicerón, las Epistulae o De Clementia de Séneca, recibidos a través de los Florilegia medievales, o bien utilizados directamente por Guillaume Perrault, Giovanni da Viterbo o Brunneto Latini, donde se encierran las claves que permiten entender los frescos de Ambrogio Lorenzetti del Buon Governo, hasta hace poco tenidos, incluso por especialistas de la talla de Rubinstein, por una manifestación más del pensamiento tomista (Skinner, 2009, 32).

No obstante, Cicerón es el escritor político favorito por los humanistas del quattrocento y "nos ha trasmitido la fórmula más corta de fundamentación de todo ello, la cual invoca la primacía de la figura humana y del ser humano entre todos los otros seres de la naturaleza: ... ómnium animantium formam vincit hominis figura" (Blumenberg, 2008, 165).

Este hecho sumado a la curiosidad por el redescubrimiento del mundo antiguo contribuyó a que

Los humanistas empezaran a instituir búsquedas sistemáticas, especialmente en las bibliotecas monásticas, de más escritos de sus autores clásicos predilectos, en particular nuevos textos de Cicerón, al que consideraban (según la frase de Petrarca en la obra, De su Propia Ignorancia) como el "gran genio" de la antigüedad. Esta búsqueda de tesoros pronto produjo toda una serie de importantes descubrimientos. Por ejemplo, todo el texto de las Cartas Familiares de Cicerón fue recuperado por Salutati en la Biblioteca de la Catedral de Milán en 1392... El obispo Landriani descubrió un manuscrito completo del Orador de Cicerón, en la Biblioteca de Lodi en $1421 \ldots$ Poggio Bracciolini... buscando en St. Gallen en 1416, recuperó una versión completa de la Retórica de Quintiliano por primera vez en el siglo IX... y dos años después, evidentemente, en Langrés, tropezó con varias oraciones de Cicerón, antes consideradas como perdidas (Skinner, $1985,107)^{11}$.

11 "La enfermedad de la curiosidad, el morbus graecus según Séneca, había sido ya diagnosticada y sometida a una terapia, en los primeros tiempos de la filosofia helenística, por el griego Epicuro... Cicerón se refería a este razonamiento a propósito de un pasaje que resulta revelador para la historia del término y del concepto de curiositas, donde presenta al epicúreo Veleyo argumentando, contra el concepto de Dios de los Estoicos, que un dios así se le impone al pensamiento del hombre como algo que lo domina incesantemente, llenándolo de miedo día y noche, pues ¿quién no va a temer a un Dios que prevé, piensa y percibe todo y al que compete todo, un Dios así de curioso y siempre atareado?" (Blumenberg, 2008, 263). 
De esta manera,

Las nuevas influencias clásicas sirvieron para enriquecer y fortalecer los géneros existentes de escritura política que ya habían brotado del estudio de la retórica, en el siglo XII, dándoles una presentación más refinada y un tono propagandístico más explícito... un ejemplo importante nos lo ofrece la sección histórica de la principal obra de Brunetto Latini, Los libros del Tesoro, compuestos en francés, en su exilio durante el decenio de $1260 \ldots$ el libro de Latini toma la forma tradicional de una enciclopedia, pero su contenido es manifiestamente la obra de un dictador de la nueva escuela que combina extensas citas de Platón, Séneca, Salustio, Juvenal y especialmente Cicerón con sus más convencionales informaciones y consejos (Skinner, 1985, 59-60).

Cicerón ha sido, evidentemente, determinado por el conflicto que él describe y que le hace reprochar con mayor acritud el desbordamiento del deseo de saber en una figura mítica e inventada que en figuras históricas:

La experiencia personal se trasluce de forma insistente, tras la cautela de sus posiciones axiológicas: Quae qui non vident, nihil unquam magnum ac cognitione dignum amaverunt. Solo puede servir para mitigar la duda sobre la tarea que hay que realizar en su vida la convicción de que hay una inmortalidad que promete compensar todo aquello que la autolimitación del deseo de saber se ha negado en atención a los deberes políticos. Eincluso esta solución platonizante recibía en Cicerón una función distinta a la que podría tener en el mundo griego. La renuncia a la teoría parece ser posible sin menoscabo de la potencia del orden práctico y político, y se trata de solucionar realmente la problemática remitiendo a un más allá: Lo que a nosotros nos gustaría hacer ahora, siempre que estemos libres de otros cuidados, a saber, quedarnos mirando y contemplando algo, esto lo podremos hacer entonces de una manera mucho más libre; alli nos podremos dedicar por completo a la contemplación e investigación de las cosas; pues en nuestro espíritu, hay, por naturaleza, una especie de ansia insaciable por conocer la verdad, y la calidad de los lugares a donde nosotros iremos intensificará tanto más nuestros deseos de conocer los fenómenos celestes cuanto más accesibles nos lo haga (Blumenberg, 2008, 280-281) ${ }^{12}$.

No obstante, una de las obras más representativas y utilizadas por los pre y renacentistas fue el documento escrito por Cicerón denominado De Oficiis. Lo "conocían, tanto por mediación del anónimo Moralium Dogma Philosophorum de mediados del siglo XII, como a través de la imponente Summae Virtutum ac Vitiorum, compilada un siglo más tarde por Guillaume Perrault. Ambas obras tenían el texto de Cicerón por auténtica Biblia en moral y filosofía política" (Skinner, 2009, 57) ${ }^{13}$ En este tratado, "el navegante se convierte en algo así como el ejecutor de la teleología de la naturaleza, la cual produce, ciertamente, de forma suficiente, todos los bienes necesarios para el hombre, pero no necesariamente en los lugares concretos en los que los hombres han decidió reunirse en comunidades, de manera que dejaría en manos del propio hombre el acercamiento y la distribución de esos bienes" (Blumenberg, 2008, $266)^{14 .}$

Cicerón había proclamado al principio de la obra, De Oficiis, exaltando el ideal del bonum commune: nosotros no hemos nacido únicamente para nosotros mismos, nuestra patria y nuestros amigos reclaman una parte de nuestra existencia... los hombres han sido engendrados por los hombres a fin de que ellos mismos puedan servir los unos a los otros, y en esto deberemos tener a la

$12 \mathrm{El}$ autor retoma lo propuesto por Cicerón en Tusculanae Disputationes, I, 44.

13Skinner comenta que según el autor J. Williams en la obra The Quest for the Author of the Moralium Dogma Philosophorum, 1931-1956, se expresa que la obra fue escrita entre 1145 y 1170 .

14 "Escribir historia era ante todo un arte literario, como lo explican algunas de las fórmulas que para ello propuso Cicerón, aunque era un arte que tenía una serie adicional de reglas relativas a la veracidad" (Burrow, 2009, 206). 
naturaleza por guía, y situar como comunes utilitates lo que a todos concierne (Skinner, 2009, 61-62).

Para los teóricos del gobierno de la ciudad, el principal recurso para la elaboración del ideal del hombre político fue Macrobio a través de su obra Comentary on the Dream of Scipio. En este sentido, el texto de Macrobio representa un importante puente intelectual entre la filosofía política romana y el tardío pensamiento republicano medieval (Paul, 1934, 248-250). El Somnium Scipionis, fue de hecho, la concluyente parte de la obra De República de Cicerón. El Commentary de Macrobio la salvó de caer en el olvido. Macrobio fue un erudito, probablemente un senador en el siglo V, nativo de la Sicilia de España. Escribió su obra Commentary, alrededor del año 430, en el siglo V d.C. y la dedicó a su hijo Eustachius o Eustatius, junto con uno de sus mayores escritos, la obra Saturnalia.

Los principales pasajes concernientes a la "virtud política" y al "hombre político" se encuentran del capítulo octavo al décimo del Libro Primero, en el que Macrobio comenta bajo las siguientes palabras que Publius Cornelius Scipio Africanus dice a su sobrino Scipio Africanus, el Joven:

...Debes ser más celoso en salvaguardar la república, Scipio, debes persuadirte de esto: todo aquello que salvas, adicionas o amplías de la república, tiene un definitivo lugar asignado en el cielo, donde se podrá disfrutar y bendecir la existencia por siempre. Nada que ocurra en la tierra, en efecto, es más gratificante para el dios supremo quien gobierna la totalidad del universo, que el establecimiento de asociaciones y federaciones de hombres regidos por principios de justicia, (Iure Sociati), los cuales son llamados repúblicas (Civitates $o$ Commonwealths). Los gobernantes $\mathrm{y}$ protectores de estas, (Rectores et Servatores), avanzarán desde aquí y retornarán del más allá después de la muerte (Macrobio, 1952, $120)^{15}$.

15 Para el texto latino, Mauricio Viroli usa la obra Commento al Somnium Scipionis.
La clave temática que se debería discutir de acuerdo con el texto de Cicerón, comenta Macrobio, es la conexión entre la persecución de la virtud política y la búsqueda de la felicidad. Esta polémica presentación es la consideración sostenida por "algunos filósofos"16. Estas virtudes pueden ser encontradas solamente en hombres devotos a la contemplación filosófica, y todos los otros, incluidos los buenos gobernantes, no podrán entonces obtener la felicidad. Para refutar este punto de vista, Macrobio se refiere a una clasificación de las virtudes dentro de la virtud política: virtudes limpiadoras, virtudes de la mente purificada, y finalmente, virtudes ejemplares (Viroli, 1992).

Como una primera síntesis encontramos que Marco Tulio Cicerón de Roma no solo marcó un lugar decisivo en la consolidación de la narrativa jurídica necesaria para estructurar los elementos del derecho que posteriormente servirán de enlace para la consolidación del Ius como la piedra angular de las sociedades modernas como se ha dicho anteriormente. De igual manera, fue el referente de consolidación del lenguaje jurídico necesario para edificar la sociedad en derecho, pero ante todo, acorde con el virtualismo cívico necesario que permitió a las sociedades en construcción obrar de acuerdo con las exigencias del Buen Governo.

\section{El ars rhetorica desde la tradición romana}

De la teoría retórica romana sobrevivieron las obras De Inventione y Ad Herennium. Ambos textos permitieron consolidar lo que se ha denominado ars rethorica. En esta construcción jurídica tan elaborada, los retóricos romanos se Susanna Morton realiza el siguiente comentario contextual en torno al tema: "Anchises language is strongly reminiscent of Cicero's reworking of the Myth of Er in the Dream of Scipio with which he closes his Republic. This text presents the fictional dream of Scipio Aemilianus in which his adoptive grandfather, Scipio Africanus, appears to him and explain how souls scape from the prison of their bodies into the only true life, life after dead. Next Scipio's natural father Aemilius Paullus, appears and explains the relative insignificance of the earth, then Africanus explains the arrangement of the planets and the 'music of the spheres and emphasises the fragility of earthly glory and of Roman activity in the world, before talking about the immortality of the soul. He closes by urging Scipio that the best life for the soul while on earth is to work for the preservation of one's country" Morton, 1997, 217).

16 Mauricio Viroli advierte que de acuerdo con P. Courcelle, Macrobio se refiere a la tradición pitagórico-platónica (Courcelle, 1973, 12). 
concentraron de forma invariable en la Inventio, la Dispositio y la Elocutio.

Etimológicamente la palabra Inventio proviene del latín Inventus y la aproximación a su significado quiere decir "idea que viene dentro de uno". Por su parte, la Dispositio es una etapa del proceso retórico de construcción de un discurso que consiste en organizar y trasformar en materia textual la estructura conceptual elaborada en la etapa de la Inventio. De otro lado, la Elocutio afecta al modo de expresar verbalmente de manera adecuada los materiales de la Inventio ordenados por la Dispositio. En la actualidad la Elocutio es lo que bien podría denominarse como Estilo.

El mismo Cicerón insiste en que entre todas las partes de la retórica, Inventio es la principal. No es para duda, pues el acto de habla se construye a partir de una creación imaginaria que trasciende a la realidad existente. De hecho, el autor anónimo de Ad Herennium, fuertemente adiciona: "de las cinco tareas del orador, él escribe, Inventio es la primera y de lejos la más difícil”. Quintiliano adiciona que por su parte, la "Elocutio, depende de la Inventio" (Skinner, 2014, 13-14).

Es decir, uno de los mayores aportes de los romanos al pensamiento jurídico consistió en que ellos hicieron referencia a la Inventio, como la manera a través de la cual pudieran descubrir y aplicar de la manera más apropiada cualquier línea de razonamiento al caso en mención.

Un ejemplo de lo anterior se puede encontrar en la obra De Oratore, de Cicerón, a través de la figura de Craso cuando señala que la tarea fundamental de un orador al hablar de cualquier tema es tener la capacidad de persuadir. Cicerón, de hecho, expone que la Inventio es el proceso de ejercitarse con cualquier afirmación específica que sea útil para presentar la probabilidad de una causa. Algo muy importante a tener en cuenta hoy, acorde con las enseñanzas del pasado, consiste en afirmar que los buenos retóricos nunca abandonarán las afirmaciones de acuerdo con los principios de moralidad.

Estos buenos principios tienen su talón de Aquiles. Es decir, la incertidumbre se genera cuando un orador con mentiras o palabras fabricadas se puede hacer pasar por verdadero. Bien lo señaló Quintiliano: un buen orador no necesariamente expresa lo que siente, también puede ser un hombre malo. No obstante, lo importante y concluyente en la construcción del entramado narrativo que consolide una buena sección argumentativa se debe fortalecer de acuerdo con los principios del Ad Herennium (Skinner, 2014, 17) ${ }^{17}$ que se pueden eslabonar en Exordium, Narratio, Divisio, Confirmatio, Confutatio y Conclusio. No obstante, respecto a esta escala de elementos de la teoría argumentativa se puede recurrir de nuevo a Cicerón, quien sintetiza al comienzo de su obra De Inventione, con una frase provista de una excepcional resonancia, que el orador ideal debe ser tomado por grande cuando combina en el más alto grado el poder de la Ratio con la Oratio o la elocuente habla (Skinner, 2014, 19).

En este sentido, la fuerza de la retórica es importante solamente en relación con aquellos tipos de argumentos en los cuales no se puede esperar proveer demostraciones, pero que sí necesitan soportar el contenido ordenando suficiente evidencia para ratificar más o menos, un caso probable (Skinner, 2014, 19) ${ }^{18 .}$

\footnotetext{
17 Skinner hace notar que "There are six different parts of a speech, he asserts, in relation to which the process of invention needs to be undertaken. The name and nature of each is then itemized: the exordium is the beginning of our speech, by means of which our audience's mind is made ready to hear our case. The Narratio is the factual account of what happened or might have happened. The Divisio is where we indicate what is agreed and what is in dispute, and where we explain what points we plan to take up. The Confirmatio is the stage at which we offer an exposition of our own arguments of our opponents. And the Conclusio is when we bring our speech to a resounding close".

18 Skinner comenta a partir de lo propuesto por Cicerón y Quintiliano: "The figure of the perfect orator whom these writers take themselves to be fashioning is accordingly said to be endowed with two closely related abilities: knowing how to invent or find out suitable arguments, and knowing how to amplify and ornament them with maximum emotional force... Quintilian adds that eloquence can be expressed in one of three distinct genera dicendi or styles of rhetorical utterance, which he labels the plain, the intermediate, and the grand... the genus grande or grand style, enforcing our arguments with figures, am-
ticenditite plifications, and other elocutionary effects".
} 
Atendiendo lo anterior, hay un principio fundamental que propone Skinner: los humanistas ingleses del Renacimiento asumieron los documentos de los retóricos y otros textos clásicos de la antigüedad como si fueran documentos contemporáneos, es decir, tuvieron un fuerte y extraordinario sentido de continuidad cultural con el cual ellos confrontaron sus autoridades clásicas, allí es donde aparece la necesidad de construir la idea de un studia humanitatis (Skinner, 2014, 26) ${ }^{19}$.

Pero en lo que respecta a la construcción jurídica, Aristóteles por su parte comenta que la genus iudiciale, es no solo la de mayor interés general, sino que es la mejor adaptada para engañar y mentir. Es decir, en la retórica judicial se puede, inclusive, tomar posición frente a lo no positivo. Por ello, cuando se habla de res o asunto de importancia pública, se comprende que la palabra res fue usada durante un tiempo para referir el contenido completo del arte de los retóricos, pero fue usualmente aplicada para describir la "materia" que fue tomada para ser usada de acuerdo con las necesidades de la investigación en un caso judicial.

No se debe olvidar que Ad Herennium fue el texto guía de los profesores de retórica en los colegios ingleses a lo largo del siglo XVI. De hecho, a comienzos del siglo hay un fuerte retorno a las prácticas educativas romanas, especialmente haciendo énfasis en la Ética de Aristóteles, De Oficiis de Cicerón y los trabajos de Platón, entre otros.

Era fundamental retornar a lo clásico. Así lo evidencia el currículo gramático de la escuela que fue en la época de los Tudor, sobrecogedoramente centrado en lo lingüístico. Por ejemplo, The Education for Children in Learning escrito por

19 Skinner argumenta: "The specific syllabus reintroduced by the humanist had been known in antiquity as the Studia Humanitatis. Quintilian in Book 10 of his Institutio Oratoria furnishes a celebrated summary of the scheme of instructions involved. As well as mastering the art of rhetoric, aspiring orators are expected to immerse themselves in the study and appreciation of poetry, history, and moral philosophy. Among the poets Quintilian gives pride of place to homer and Virgil; among the historians he singles out Thucydides and Herodotus...".
William Kempe y publicado en 1588. Kempe recomendó que durante los primeros cinco años de escolaridad los niños aprendieran latín, posteriormente se deberían introducir en el estudio de la lógica y la retórica, pero con un continuo énfasis en el uso del latín para escribir algunos temas en el propio estilo retórico. Kempe centró su apoyo en las obras Studia Humanitatis, Ars Grammatica y Ars Rhetorica.

Otro autor clave fue Juan Luis Vives (1493-1540) quien llegó a Inglaterra para enseñar humanidades en Oxford en 1523. Vives utilizó De Tradendis Disciplinis de 1531. Adicional a ello, Vives recomendaba los textos clásicos de Quintiliano, pero el manual más popular fue Ad Herennium y la introducción que invitaba a usar los trabajos de Cicerón, especialmente De Inventione y De Partitione Oratoria. Junto con los autores, también se consolidaron normativas en torno a la orientación de los escolares (Skinner, 2014, $28)^{20 .}$

Otro de los ejercicios interesantes a través de los cuales proliferó la idea de retornar y utilizar los textos clásicos se dio con el descubrimiento y uso de la imprenta, porque a partir de ella se empezaron a dar los permisos necesarios para los ejercicios de impresión. Por ejemplo, Henry Bynneman en 1569 recibió una patente para publicar libros clásicos para uso de la Escuela Jhon Kingston. Fue uno de los primeros impresores en publicar un interesante número de textos retóricos que incluyeron una edición de la obra de Erasmo, De Copia en 1569. En 1573 Kingston publicó las obras de Cicerón, De Oratore y en 1574, De Inventione. Por su parte, publicó Ad Herennium, haciendo uso de la versión original publicada por Gymnich en 1535. Otros impresores fueron Jean Deserrans, Thomas

20 Skinner comenta: "The surviving statutes of the Tudor grammar schools show that this advice was widely taken up. The "laws" drawn up in 1550 for King Edward, VI Grammar School at bury St Edmunds state that, in the most senior form, "the master should read Quintilian 's Instituto Oratoria, or else the precepts of Rhetoric contained in the Ad Herennium. The Ordinances of 1556 for Norwich Grammar School likewise specify that Quintilian and the Ad Herennium Should be read "in the highest fourme". The 1574 statutes of the free Grammar School at Leicester... the 1576 statutes of Rivington School was similary...". 
Marsh y Thomas Vautrollier, quien imprimió una de las más renombradas traducciones, la versión de Thomas North de Plutarco que aparece como The Lives of the Noble Grecians and Romanes. Sin embargo, el más llamativo fue Richard Field, que terminó siendo familiar de William Shakespeare y publicó algunas de sus obras iniciales (Skinner, 2014, 43) ${ }^{21}$.

Sin embargo, y a pesar del sinnúmero de autores, Thomas Wilson (1524-1581) quien fuera educado en humanidades en Cambridge, fue el primero en publicar un trabajo sobre lógica, el primero publicado en inglés, denominado The Rule of Reason de 1551. El otro trabajo fue Ars of Rhetorique, primera edición en 1553. Wilson retorna a los tópicos clásicos cuando afirma que "cada teoría sistemática de argumentación contiene dos partes, Inventio y Juicio". Además establece una gran diferencia entre lógica y retórica. A partir de los textos clásicos, el gran aporte de Wilson fue la creación de los conceptos de oración demostrativa, oración deliberativa y oración judicial (Skinner, 2014, 46-47) ${ }^{22 .}$

Durante la Inglaterra de los Tudor, los ejercicios de retórica tendieron a seguir la idea aristotélica de las cuatro partes que conforman una oración. Shakespeare siguió este tipo de división sumado a la marcada influencia que tuvo Ad Herennium y De Inventione de Cicerón (Skinner, 2014, 33) 23. $^{2}$ De hecho, para Wilson el líder político que sabe cómo combinar ratio con oratio es el héroe, de acuerdo con lo planteado en su libro.

21 Según Skinner, "First there is the Oration demonstrative... next comes the Oration deliberative... finally there is the Oration Judicial, which Wilson regards by far the most important, and which he proceeds to define in solemn terms: Oration Judiciall is, an earnest debatyng in open assemblie of some weightie matter before a judge, where the complainaunt commenseth his action, \& the defendaunt thereupon aunswerwth at his peril to al suche thynges as are laied to his charge..."

22. Skinner comenta que Shakespeare "was closely acquainted with the arguments of the De Inventione and Ad Herennium about how to construct forensic speeches, and sometimes directly quotes them. He seems in addition to have studied a number of vernacular rhetorical text, including Thomas Wilson's Arte of Rhetorique, to which he also makes explicit reference".

23 De acuerdo con Skinner, "Field achieved his most spectacular success. He printed and published John Harington's translation of Orlando Furioso in 1591. He printed some poems by George Chapman in 1594, as well as his translation of Homer in 1611 and 1614. He produced the first complete edition of Edmund Spenser's Faerie Queene in

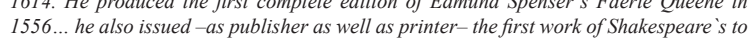
be published, his Venus and Adonis of 1593".

\section{Shakespeare in juridical context}

Shakespeare compuso varios escritos en los que se evidencia la utilización de variables retomadas de los clásicos, tales como genus demonstratium $y$ genus deliberativum, es decir, elementos propios de la retórica jurídica. Es posible rastrear que el origen de su escritura que apunta a la retórica jurídica lo tuvo en los retóricos clásicos que le enseñaron acerca de cómo hablar en la corte, y aún más, cómo hablar, "concerned with the importance of winning goodwill at the outset of a speech" (Skinner, 2014, 50). Sin embargo, no hay que olvidar que la primera obra en la que Shakespeare hace referencia a las técnicas judiciales es The Comedie of Errors de 1590.

En 1594 publicó la obra Lucrece, allí se evidencia la exploración de dos conceptos trascendentales en la escena jurídica: la responsabilidad y el remordimiento. Su profesor, Richard Field que formaba parte de The London Printing House, había realizado la impresión de un solo volumen llamado Rhetoricum ad C. Herennium Libri Quattor. M.T. Ciceronis De Inventione Libri Duo en 1579.

Como impresor, Field publica Venus and Adonis en 1593, un año después, Lucrece. Es posible afirmar entonces que Richard Field le entregara a Shakespeare el Libri Duo. Ello se evidencia en que los escritos posteriores a la publicación y el conocimiento de este libro por parte de Shakespeare, le permiten escribir acorde a las técnicas utilizadas en la retórica judicial, ello se evidencia en los nuevos detalles de complejidad que se trazan en sus escritos. De hecho, el primer texto en el cual se encuentra la evidencia de lo aprendido es en Romeo y Julieta, posiblemente escrito en la segunda mitad de 1595. Luego van a aparecer bosquejos de los principios de retórica judicial en The Merchant of Venice, escrito entre 1596 y 1597, igualmente en Hamlet de 1600. 
Precisamente es en Hamlet que de nuevo se evidencia la más compleja forma de oratoria judicial: la Constitutio Coniecturalis. De hecho, en Hamlet se compromete con los principios de la genus iudiciale en un elevado nivel de complejidad. En esta obra Shakespeare revela una profunda preocupación con la teoría de la "Forensic Eloquence" que en uno de sus primeros trabajos incluye la narración del vocabulario técnico desarrollado por los retóricos para distinguir el genus iudiciale. Este vocabulario se centró alrededor de dos términos relacionados. En el primero, los escritores clásicos hacen referencia a la res o alcance de la materia que es utilizada en los juicios al momento de declarar. Recolectando esta terminología, los retóricos vernáculos hablan de la "materia" como aquella que necesariamente permanece en la investigación y el juicio.

En el segundo, los escritores clásicos observan que al hablar de aquellas materias de adjudicación, se está apuntando al hecho de que debería ser la cuestión en controversia la que se necesita para argumentar en ambos sentidos del caso. Es decir, una importante conclusión permite comprender que Shakespeare usó los principios expuestos en la retórica judicial combinados con una técnica dramatúrgica. Lo importante es que se dramatiza la más compleja forma de retórica judicial, la Constitutio Coniecturalis.

Otro aspecto importante consistió en que la mayoría de las construcciones textuales fueron elaboradas acorde a las reglas clásicas que gobiernan la Inventio y la Dispositio utilizadas en los argumentos jurídicos. Especialmente en la secuencia, no necesariamente lógica, de Prohormium, Narratio, Confirmatio, Confitatio y Peroratio.

Es muy importante en términos contextuales comprender cómo estos términos latinos fueron trasladados y asimilados en el tiempo que Shakespeare escribía sus obras. Un primer elemento de comprensión es ver qué tipo de documentos se habían escrito. En este orden de ideas, el documento más antiguo al respecto es la obra de Thomas Cooper denominada Thesaurus Linguae Romanae \& Britanaicae, publicada originalmente en 1565. La siguiente fue la obra Dictonaire in Latine and English de John Verón que apareció en su primera publicación en 1575 y fue reimpresa en 1584. Estos trabajos tiempo después fueron reemplazados por el Dictionarium Linguae Latinae or Anglicanae de Thomas Thomas de 1587, posteriormente publicado en 1589 y 1592 y así sucesivamente hasta finales del siglo XVI.

Otro de los conceptos claves que se construye en este escenario de tiempo es el relacionado con el significado de los adjetivos honestus $\mathrm{y}$ turpis. Todos ellos coincidieron en afirmar que la palabra turpis significa deshonesto. De hecho, más amablemente ellos adicionaron que uno de los sinónimos básicos de esta palabra es falta (foul) que combinada en inglés de la siguiente manera foul play, va a ser designada para describir serios crímenes que especialmente tienen relación con la muerte.

Entonces, si turpis es falta o deshonestidad, su antónimo debe ser honestus. En este sentido, los lexicógrafos la adicionan como honesto. De allí se desprendieron varios sinónimos como por ejemplo, bueno, buena reputación, virtuoso, noble y honorable. A su vez esta extensión en el uso de las palabras se desprende aplicando al lenguaje jurídico, causa turpis o causa honesta, de la que ya había hablado Cicerón y Quintiliano cuando la presentan como causa admirabilis.

Ahora bien, dependiendo de estas causas, como lo señala Ad Herennium, se abren dos clases de uso en la retórica, el principium y la insinuatio. Si la causa es honesta se debe usar el primero de ellos. Pero si la causa es falsa, se debe usar una insinuante aproximación, es decir, un acto de habla que se construya desde la insinuatio. Al 
final lo que se buscaba en derecho como lo señaló el satírico Philibert de Vienne en su obra The Philosopher of the Court, traducida por George North en 1575 es demostrar que la palabra de la corte es una con la cual, "honor y reputación es la conclusión final de nuestra virtud”.

De hecho, en las actuaciones jurídicas, para llenar a los adversarios de odio, se comenta en Ad Herennium se propone que sean descritos como spurcus, una palabra usualmente traducida en los diccionarios latín-inglés como sucio, inmundo, pero con la connotación de inmoral, indecente, impuro, adultero y corrupto. Un claro ejemplo de ello se presenta en el periodo en el cual Shakespeare estuvo más preocupado por el uso de lo concerniente al genus iudiciale, especialmente cuando compuso la obra Measure for Measure. También, George Whetstone en su obra Promos and Cassandra de 1578, en que expone la historia de un juicio corrupto, en el que Promos demanda a una joven y virtuosa mujer llamada Cassandra.

Otro de los inventos que se crean y usan es el denominado Epanodos, una figura del habla en la cual como Dudley Fenner explica, el mismo sonido (palabra) es repetido al comienzo y a la mitad, en la mitad y al final de la sentencia. La Paralepsis, denominada también Occultatio, es una figura literaria acorde al Ad Herennium, que consiste en argumentar que no se necesita decir algo, cuando de hecho, es mucho más lo que se quiere decir. Henry Peacham adiciona que cuando un orador hace uso de esta técnica está demostrando que aunque no diga mucho, el orador expresa que en realidad hay mucho que decir de ello.

Hay muchos conceptos más, que bien se podrían resumir así: Mimesis de Richard Sherry, quien también habló en detalle de las formas naturales de la Prueba, Aposeopesis y Epanodos de Dudley Fenner; Paralepsis de Henry Peacham; Rethorical Dilatio de Thomas Wilson; Dilatio de Richard Rainolde y Tapinosis de George Puttenham. Leonard Cox aportó con la narración en la retórica jurídica y así muchos más.

De hecho, todos y cada uno de los autores anteriores coinciden en retornar de manera necesaria al libro 4 de la obra Instituto Oratoria de Quintiliano en que expresa que la llave de la lucidez y la verosimilitud es la brevedad. Todos los anteriores enfocados a lo que en su momento Quintiliano expresó: el arte de la retórica no se centra tanto en los contenidos, sino en el poder de persuadir. De hecho, la Retórica es considerada la ciencia de "hablar bien".

Un estudio pionero del concepto y su lugar en el Common Law, fue el escrito por Christopher Saint Germán en su diálogo Doctor and Student, publicado por primera vez en latín en 1528, traducido al inglés en 1530 y reimpreso en varias ocasiones hasta el final del siglo XVI. Acorde a la figura del Doctor en el primer diálogo, se menciona que para seguir las palabras precisas de la ley se deben seguir las instancias precisas.

Para los retóricos hay dos cuestiones morales interconectadas. La primera, como lo propone Ad Herennium, la construcción de un argumento a partir de la verdad conforme a la evidencia posible. Esto lo ratificó Leonard Cox en su obra Art or Crafte of Rhetoryk.

Este ejercicio de Veracidad y Pruebas fue llamado por los retóricos clásicos como Quarere. Esto es confirmado por Thomas Cooper en su obra Thesaurus y por John Verón en su Dictionarie. Más explícitamente, Thomas Wilson sintetiza en 1553 que el Quarere es " $a$ matter of searchyng out the substance, or nature of the cause" (Skinner, 2014, 227).

Los retóricos clásicos dieron fuertes razones para creer que el uso adecuado de los términos podía producir efectos emocionales poderosos, como los utilizados en Hamlet. En el mismo 
sentido habló Cicerón cuando hizo referencia a Illustris Explanatio. Quintiliano hace mención al mismo concepto, a partir del vocablo aristotélico denominado Enargeia y su variación, Enargeia as Representatio de la que comenta: "the effect, as he says will be to penétrate and arouse their emotions with a forcé that no mere description can ever hope to achieve" (Skinner, 2014, 238). De acuerdo con los aportes de Ad Herennium, la cuestión de cómo responder efectivamente a una acusación no requiere de una especial dificultad pues usa Confirmatio para producir de manera implacable una Refutatio. De esta manera, se consolida la red de conceptos que armarán el ralo tejido jurídico que posteriormente se consolidará y llegará a muchos lugares del mundo en los que, salvo algunas variaciones, se sigue usando de la misma forma.

\section{Conclusiones}

Es necesario retornar a las obras clásicas para generar procesos de pensamiento que aborden lo que la moderna sociedad de consumo con sus avasalladoras tendencias tecnológicas han dejado de lado: los seres humanos y su desenvolvimiento social, político y económico. Hay que pensar en las fallas eventuales presentadas en un sistema que al final ha tenido como parte de su trama los vestigios del pensamiento clásico expresado a través de los autores y sus obras.

Se ha podido permear a través de los escritos de los teóricos actuales de diferentes escuelas y líneas académicas, una creciente tendencia a fortalecer parte de sus argumentos narrativos con los autores y los denominados textos clásicos. Ello implica que no en vano se debe realizar una relectura de estos aportes, especialmente hoy que la sociedad está inmersa en una profunda crisis de letargo.

Sin duda, la idea del Buen Governo sí es posible. Ambroggio Lorenzetti lo expresa en sus frescos del Palacio Comunal de Siena en Italia. Por ello hay que recurrir a las enseñanzas de su construcción que ya desde Macrobio aparecieron con la idea de que el gobernante de la ciudad debería poseer las virtudes políticas de la prudencia, la fortuna, la templanza y la justicia. La posesión y exhibición de aquellas virtudes le permitirían al hombre político llegar a gobernar la ciudad en el sentido ciceroniano, es decir, una comunidad de hombres, siempre unidos y regidos por principios de justicia.

Marco Tulio Cicerón de Roma marcó un lugar decisivo en la consolidación de la narrativa jurídica necesaria para ir estructurando los elementos del derecho que posteriormente servirían de enlace para la consolidación del Ius como la piedra angular de las sociedades modernas. Se concluye que otro de los grandes aportes de Cicerón a partir de su obra De Inventione, fue la construcción de dos cualidades cardinales para hablar de manera persuasiva y convencer: la ratio o razón en combinación con oratio o el poder del habla o la oratoria. Además, Cicerón no solo marcó un lugar decisivo en la consolidación de la narrativa jurídica. De igual manera, fue el referente de consolidación del lenguaje jurídico necesario para edificar la sociedad en derecho, pero ante todo, acorde al virtualismo cívico necesario que permitió a las sociedades en construcción obrar acorde a las exigencias del Buen Governo.

El estudio del republicanismo es fundamental en estos momentos de la historia. Especialmente ahora que hay un fuerte retorno a los gobiernos de derecha, al nacionalismo moderado que puede convertirse en xenófobo y a la exclusión de no nacionales en el eje global. Precisamente la fuerza que ha tomado el estudio del republicanismo y las virtudes cívicas hará posibles trasformaciones en los gobiernos internacionales.

Shakespeare compuso varios escritos en los que se evidencia la utilización de variables retomadas de los clásicos, tales como genus demonstratium 
y genus deliberativum, es decir, elementos propios de la retórica jurídica. Es posible rastrear que el origen de su escritura que apunta a la retórica jurídica lo tuvo en los retóricos clásicos que le enseñaron acerca de cómo hablar en la corte.

Los elementos de la narrativa jurídica heredados del pensamiento clásico se utilizaron en conversaciones, diálogos, en conversaciones domésticas y escenarios jurídicos, entre otros. Dentro de las actuaciones de los personajes de las obras de Shakespeare, siempre se utilizó para acusar o defenderse una oración jurídica completa. Además, siempre incluyó en sus oraciones Prohoemium, Naratio, Confirmatio o Refutatio y Peroratio.

Shakespeare nunca escribió en un orden preestablecido por los mandatos del genus iudiciale, lo hizo distribuyendo invariablemente secciones individuales entre los diferentes actores de los diálogos. Pero sí es evidente que Shakespeare realizó investigación y conoció de primera mano lo pertinente a las formas jurídicas para fortalecer sus versos en rima.

Una importante conclusión de Skinner tras la investigación es que la obra Measure for Measure fue probablemente escrita también después de Othello. Como All's Well fue probablemente escrita también después de Measure for Measure. Skinner ha establecido el final de esta obra por parte de Shakespeare hacia los primeros meses de 1605 .

\section{Referencias bibliográficas}

Bocardo, E. (2007). El giro contextual: cinco ensayos de Quentin Skinner y seis comentarios. Madrid: Tecnos.

Blumenberg, H. (2008). La legitimidad de la Edad Moderna. Valencia: Pre-Textos.
Blumenberg, H. (2009). La risa de la muchacha tracia. Valencia: Pre-Textos.

Burrow, J. (2009). Historia de las historias. Barcelona: Crítica.

Courcelle, P. (1973). Recherches sur Saint Ambroise. París.

Friedrich, C.J. (1997). La filosofía del Derecho. México: Fondo de Cultura Económica.

Judt, T. y Snyder, T. (2012). Pensar el siglo XX. Bogotá: Taurus.

Macrobio. (1952). Commentary on the Dream of Scipio. New York.

Martínez, C. (2006). Quentin Skinner y la mirada profunda de la historia política. Revista del Centro de Historia de Casanare: Caribabare 16, 33-62.

Martínez, C. (2012). Quentin Skinner y el giro contextual en la historia de las ideas políticas. Revista de Santander 7, 78-85.

Martínez, C. (2013). El buen gobierno como modelo para la generación de inclusión social y competitividad. En: Emprendimiento Sostenible. Bogotá: EAN, 247-274.

Martínez, C. (2014). Quentin Skinner: la idea de la libertad. Revista de Ciencias Sociales: Comunicación, Cultura y Política 2 (5), 7-30.

Martínez, C. (2014). Quentin Skinner y la Escuela de Cambridge. Papeles. Revista de la Facultad de Ciencias de la Educación 10 (5), 9-20.

Morton, S. (1997). Virgil and the Cosmos: Religious and Philosophical Ideas. En: Martindale, C. (Ed.). The Cambridge Companion to Virgil. London: Cambridge University Press. 
Paul, H. (1934). Plotin et l' Occident.

Regali, M. (1983). Commento al Somnium Scipionis. Pisa.

Ricoeur, P. (2008). La memoria, la historia, el olvido. Buenos Aires: Fondo de Cultura Económica.

Skinner, Q. (1985). Los fundamentos del pensamiento político moderno. México: Fondo de Cultura Económica.

Skinner, Q. (2002). Vision of Politics:

Renaissance Virtues. London: Cambridge

University Press.

Skinner, Q. (2009). El artista y la filosofía política: el buen gobierno de Ambrogio Lorenzetti. Madrid: Trotta.

Skinner, Q. (2014). Forensic Shakespeare. London: Oxford University Press.

Tarrant, R.J. (1997). Poetry and Power: Virgil's Poetry in Contemporany Context. En: Martindale, C. (Ed.). The Cambridge Companion to Virgil. London: Cambridge University Press.

Viroli, M. (1992). From Politics to Reason of State: The Acquisition and Transformation of the Language of Politics: 1250-1600. England: Cambridge.

Williams, J. The Quest for the Author of the Moralium Dogma Philosophorum, 1931-1956. 